\section{DOCUMENTOS}

\section{CNI/ Dampi e Senai - DN/Ciet}

\section{Resumo}

A Pesquisa de Demanda por Informação Tecnológica pelo Setor Produtivo, surgida no âmbito da Subcomissão de Informação Tecnológica do Programa de Apoio à Capacitação Tecnológica da Indústria (PACTI) e realizada em 1996, busca identificar as necessidades de informação por parte do setor industrial, com o objetivo de suprir as instituições/centros provedores de informação tecnológica com dados acerca do mercado demandante para que estes possam adequar melhor os seus produtos e serviços.

\section{Palavras-chave} informação; Setor produtivo.

\title{
Pesquisa de demanda por informação tecnológica pelo setor produtivo 1
}

\section{ASPECTOS METODOLÓGICOS}

A pesquisa de Demanda por Informação Tecnológica pelo Setor Produtivo, realizada em 1996 e sob a coordenação da CNI/Departamento de Assistência a Pequena e Média Indústria (Dampi) e Senai/DN - Centro Internacional para a Educação, Trabalho e Transferência de Tecnologia (CIET), teve por objetivo captar as necessidades e demandas da área industrial com relação à informação tecnológica nos seguintes aspectos:

- comportamento das indústrias diante do uso e necessidade de informação de natureza tecnológica;

- as principais fontes, produtos e serviços de informação utilizados pelas indústrias;

- uso da informação como estratégia para o desenvolvimento de produtos, processos, gestão e para o processo de transformação;

- produtos/serviços de informação tecnológica mais adequados às indústrias.

Diante da carência de dados acerca das demandas do setor produtivo, a Subcomissão de Informação Tecnológica do PACTI estabeleceu a realização da pesquisa como uma das prioridades dentre suas atividades.

Levando-se em conta a heterogeneidade das empresas da área industrial, o desenho da pesquisa procurou distingui-las segundo o setor de atividade econômica a que pertenciam (segundo classificação do IBGE, agrupada em setores) e o porte em termos do número de empregados. Por limitações amostrais, ressaltase que os resultados aqui apresentados devem ser lidos com restrições, na medida em que representam respostas das 1990 empresas que responderam ao questionário, não sendo estas, necessariamente, representativas do universo empresarial. Além disto, optou-se pela não-regionalização da amostra, dado que isto envolveria um volume muito grande de informantes, e o propósito do estudo inicialmente era o de subsidiar os núcleos especializados setorialmente da Rede PADCT/IBICT. Ainda assim, a análise mais detalhada dos dados possibilita identificar diferenças importantes quanto ao comportamento das empresas industriais de acordo com o setor/porte a que pertencem.

A amostra da pesquisa foi desenhada separadamente para pequenas, médias e grandes empresas (a cargo da CNI/Dampi e CIET-Senai/DN) e para microempresas (a cargo do Sebrae), tendo a seguinte configuração:

${ }^{1} \mathrm{CNI} /$ Dampi, Senai/Ciet. Síntese elaborada a partir da pesquisa de demanda por informação tecnológica pelo setor produtivo, 1996. Para a obtenção da versão completa da pesquisa, acessar o site do Ciet - http://www.ciet.senai.br. 
- 1550 indústrias extraídas do Cadastro RAIS/91

- 2100 pequenas e médias indústrias que participam da Sondagem Empresarial da Pequena e Média Indústria da CNI

Para a determinação de porte da indústria, utilizou-se a seguinte tipologia:

- até 19 empregados, microempresa;

- de 20 a 99 empregados, pequena;

- de 100 a 499 empregados, média;

- mais de 500 empregados, grande.

Quanto aos setores de atividade econômica, estes foram definidos da seguinte forma:

- metalurgia/minerais metálicos e não metálicos;

- mecânica;

- material elétrico e eletrônico e de comunicações;

- madeira/mobiliário;

- celulose, papel e papelão;

- borracha/plástico;

- couros, peles, calçados e afins;

- química;

- têxtil/vestuário;

- alimentos/bebidas;

- outros ramos.

As empresas industriais que responderam ao questionário (1990) apresentaram as seguintes distribuições por porte e por setor de atividade:

Porte

Questionários respondidos

Micro

(até 19 empregados)

\section{Média}

Grande

(acima de 500 empregados)

2 Inclui 27 indústrias da amostra RAIS/Sondagem Empresarial que retornaram como microempresas. 
Material elétrico e eletrônico e de comunicações

Um estudo deste porte, em âmbito nacional, representa um importante subsídio para as instituições provedoras de informação tecnológica no que tange às possibilidades de aperfeiçoamento e desenvolvimento ou, até, de expansão de produtos e serviços de informação a partir do conhecimento mais preciso do mercado demandante.

\section{Resultados}

\section{Na busca por informações, sua empresa já consultou alguma das instituições listadas?}

\section{Instituições}

a. Indústrias do ramo

b. Empresas de consultoria/engenharia

c. Agência de financiamento/bancos públícos e privados

d. Entidades/associações de classe empresariais

e. Órgãos do governo

f. Instituto de pesquisa e desenvolvimento/universidades

g. Sistema CNI/Senai

h. Sistema Sebrae

i. Outras instituições

Os resultados da pesquisa como um todo revelam inicialmente que 347 empresas industriais nunca consultaram nenhuma instituição em busca de informação tecnológica, ou seja, cerca de $17 \%$ dos informantes. Entre aquelas que o fizeram, a maior parcela $(46,0 \%)$ recorreu a indústrias do ramo para suprir as necessidades de informação, seguidas do Sistema $S_{\text {Sebrae }}^{3}$ e agências de financiamento/bancos públicos e privados (35,5\% e $34,9 \%$ das empresas, respectivamente), entidades/associações de classe (27,7\%), Sistema CNI/Senai/Federações Estaduais de Indústrias (24,5\%), empresas de consultoria/engenharia $(23,5 \%)$ e órgãos do governo (19,1\%). As instituições menos consultadas foram os institutos de P\&D/universidades (14,5\%), denotando a reduzida freqüência, em termos quantitativos, das relações de interação entre o meio acadêmico e o setor industrial.

\footnotetext{
${ }^{3}$ Ressalta-se que quaisquer informações relativas às microempresas devem ser lidas tendo-se em mente que metodologicamente a amostra para microempresas industriais e a amostra para pequenas, médias e grandes empresas foram definidas independentemente. Portanto, pode ocorrer um certo viés na interpretação dos resultados, quando estes não estão separados por porte. Quando isto ocorrer, a própria análise das informações enfatizará as diferenças. Como ilustração, no caso desta questão, os resultados para pequenas, médias e grandes indústrias, separadamente, indicam, em ordem decrescente de freqüência: indústrias do ramo $(54,0 \%)$, agências de financiamento/bancos públicos e privados (46,8\%) e, em sexta posição, Sistema Sebrae, com 33,0\% das respostas.
} 

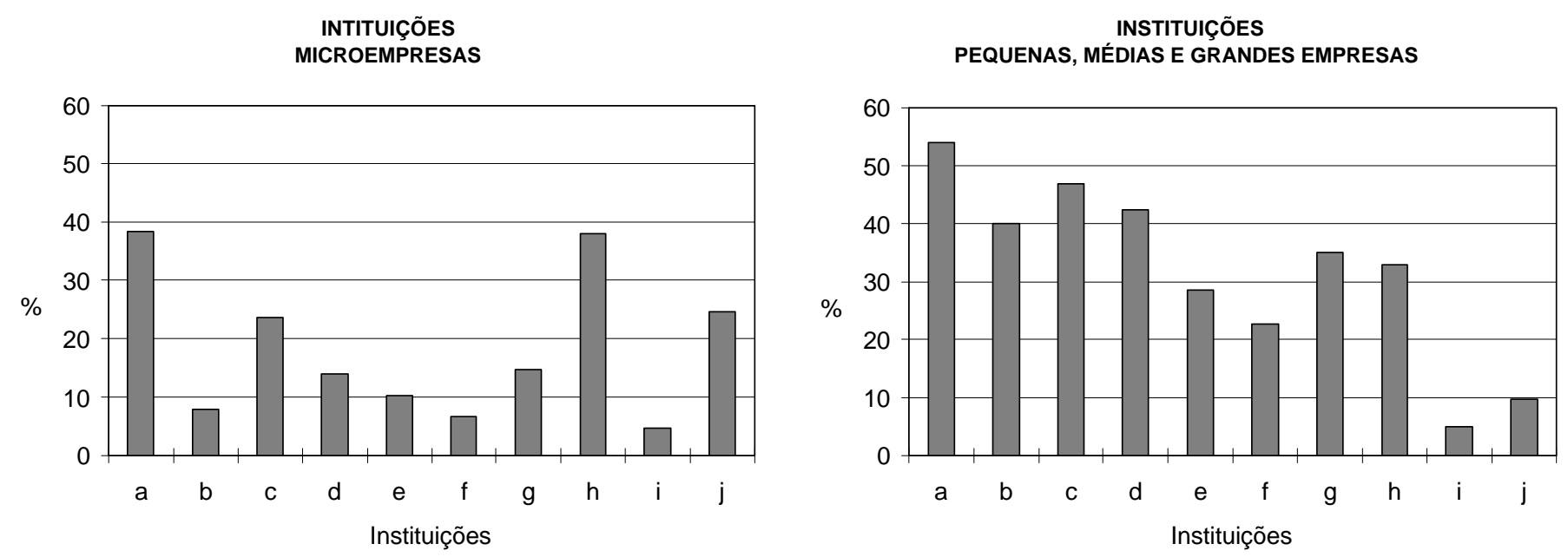

\section{Que tipos de informação sua empresa buscou nas instituições listadas?}

Tipos de informação

a. Fontes de financiamento

b. Fornecedores de máquinas e equipamentos

c. Fornecedores de matérias-primas/insumos

d. Proc. produção/contr. qualidade/gestão organizacional

e. Treinamento de recursos humanos

f. Assistência técnica

g. Extensão tecnológica

h. Merc. atuação/oportun. negócios/parcerias/...

i. Transf.tecnologia/normas técnicas/propr. industrial

j. Histórico de uma tecnologia (estado-da-arte)

I. Publicações técnicas

Quanto ao tipo de informação solicitada junto às instituições, a de menor procura foi aquela relativa ao levantamento do histórico de uma tecnologia até seu estado atual (apenas 3,4\% das empresas industriais). As três principais informações mais procuradas pelas empresas foram, em ordem decrescente de freqüência, fontes de financiamento (42,9\%), processo de produção/controle de qualidade/gestão organizacional (35,3\%) e fornecedores de máquinas e equipamentos (33,3\%). Ressalta-se novamente o viés causado pela incorporação das microempresas no resultado total, pois, no caso das pequenas, médias e grandes indústrias, aparece com destaque treinamento de recursos humanos (41,9\%), que suplanta o percentual de citações para fornecedores de máquinas e equipamentos $(39,7 \%)$.
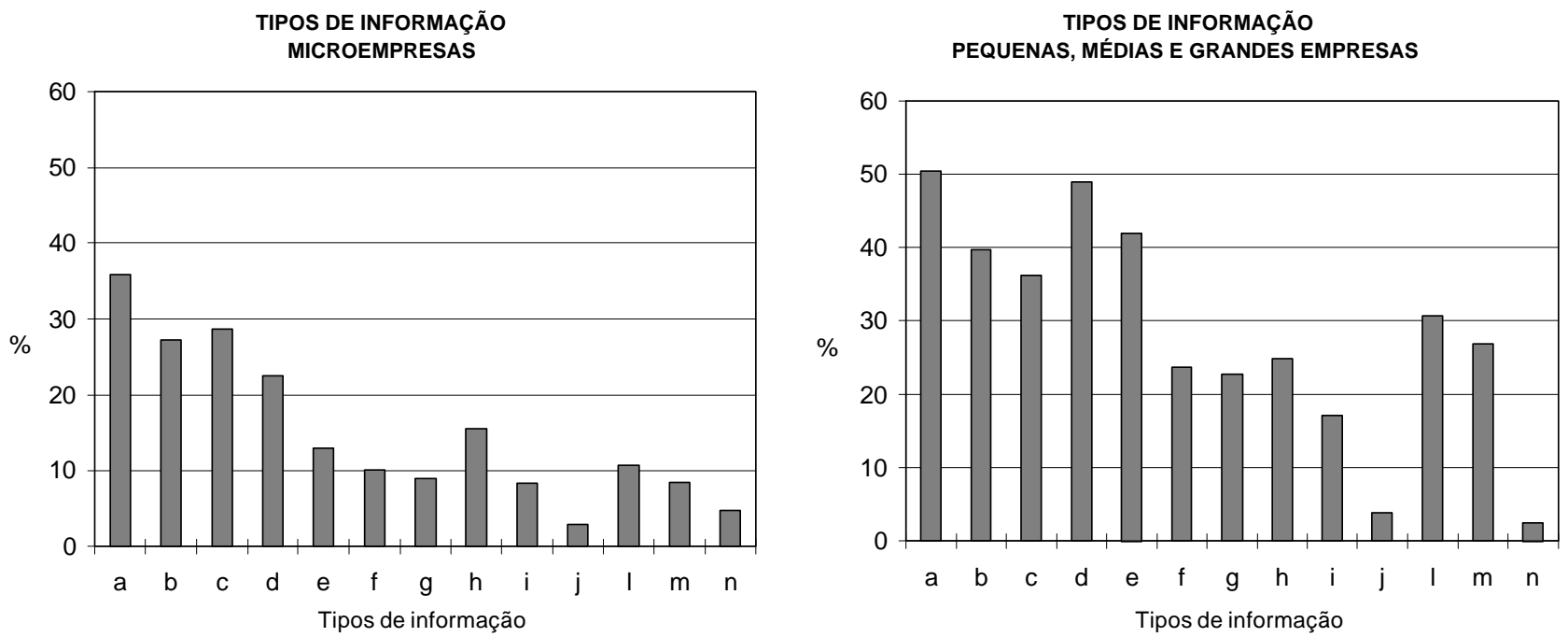
a. Desconhece centros/serviços de informação

b. Falta de divulgação das informações existentes

c. Descrédito nas informações/falta de credibilidade

d. Pessoal de atendimento não qualificado

e. Excesso de burocracia

f. Desinteresse/demora no atendimento

g. Desatualização/irrelevância das informações

h. Veículos de divulgação inadequados

i. Informações em idioma estrangeiro

j. Custo elevado dos serviços

Na relação com as instituições ofertantes de informação tecnológica, as maiores dificuldades no acesso às informações derivaram do excesso de burocracia $(39,3 \%$ das respostas), seguido de falta de divulgação das informações existentes $(36,4 \%)$, o que representa a necessidade de as instituições reverem os métodos de trabalho, dinamizando o atendimento, e estabelecendo políticas firmes de divulgação dos seus produtos/serviços. O desconhecimento da existência dos centros/ serviços de informação aparece em terceiro lugar, citado por $28,3 \%$ das empresas. Quanto às dificuldades menos citadas pelos informantes, constam o fornecimento de informações em idioma estrangeiro (3,5\%), veículos de divulgação inadequados $(9,1 \%)$ e desatualização/irrelevância das informações $(9,8 \%)$. Ressalta-se que o custo elevado dos serviços é citado como dificuldade na busca por informações de $22,8 \%$ dos informantes.

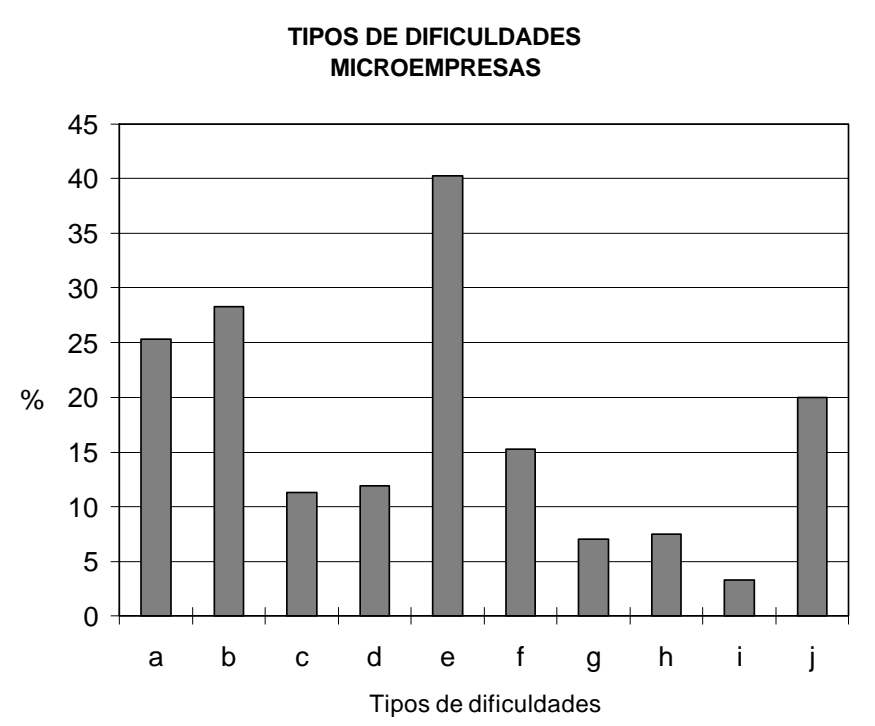

TIPOS DE DIFICULDADES

PEQUENAS, MÉDIAS E GRANDES EMPRESAS

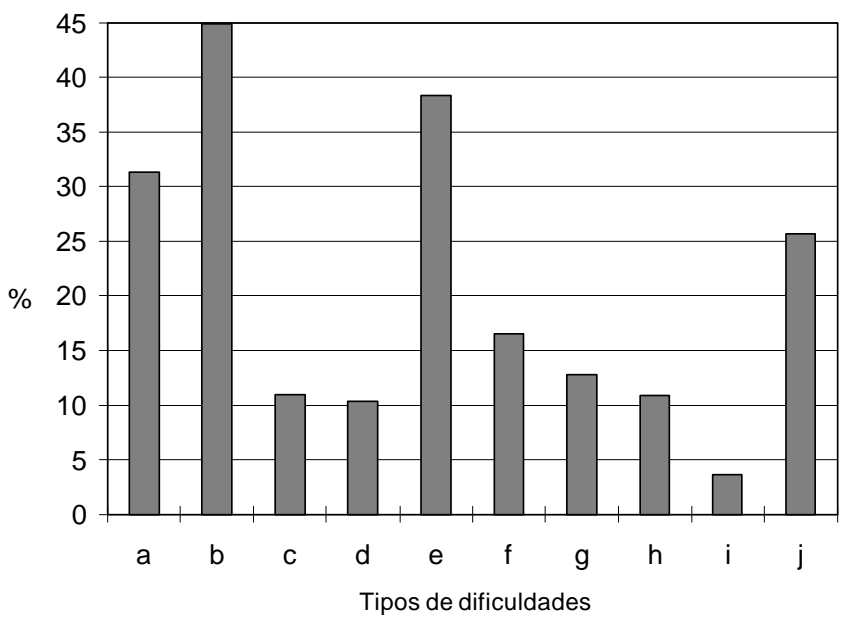

\section{Quais as fontes de informação mais utilizadas por sua empresa?}

Fontes de informação

a. Recursos da própria empresa

b. Fornecedores/fabricantes

c. Consultores/especialistas

d. Feiras e exposições

g. Publicações especializadas

h. Normas e regulamentos técnicos

i. Marcas e patentes

Entre as fontes de informação mais utilizadas pelas empresas industriais, aparecem majoritariamente os recursos da própria empresa, citados por $62,6 \%$ dos informantes, fornecedores/fabricantes, citados por $54,0 \%$ e publicações especializadas (47,2\%). Em contrapartida, bases de dados armazenadas em meio magnético (4,5\%) e marcas e patentes $(7,7 \%)$ são as fontes menos consultadas, sendo que a baixa utilização no último caso - marcas e patentes - reflete a pouca familiaridade/desconhecimento, pela expressiva maioria das empresas, da riqueza das informações contidas nos documentos de patentes como informação tecnológica. 


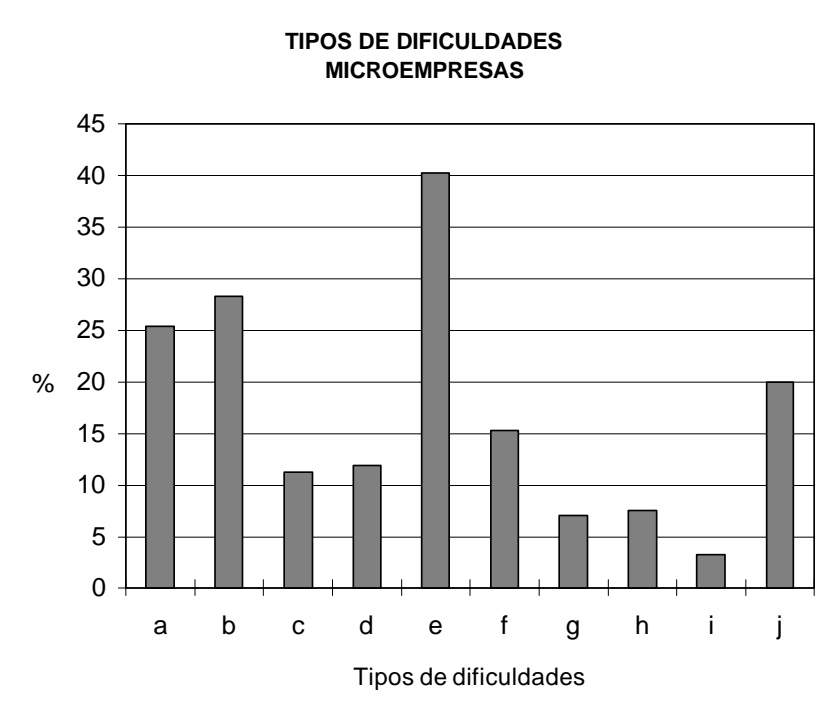

TIPOS DE DIFICULDADES

PEQUENAS, MÉDIAS E GRANDES EMPRESAS

\section{Quais os veículos de acesso às informações de que dispõe sua empresa?}

Veículos de acesso

a. Telefone

b. Telex

c. Fax

d. Computadores

e. Leitora de CD-ROM

f. Redes de Comunicação Nacionais

g. Redes de Comunicação Internacionais

Do ponto de vista dos veículos de acesso às informações disponíveis nas empresas, os tradicionais aparecem em parcelas significativas dos informantes: telefone $(97,8 \%)$ e fax $(85,7 \%)$. Os computadores estão presentes em $58,5 \%$ das empresas $^{4}$, sendo que, destes, $19,6 \%$ possuem leitora de CD-ROM, 13,7\% estão conectados a redes de comunicação eletrônica nacionais e 8,8\% a redes de comunicação eletrônica internacionais ${ }^{5}$.

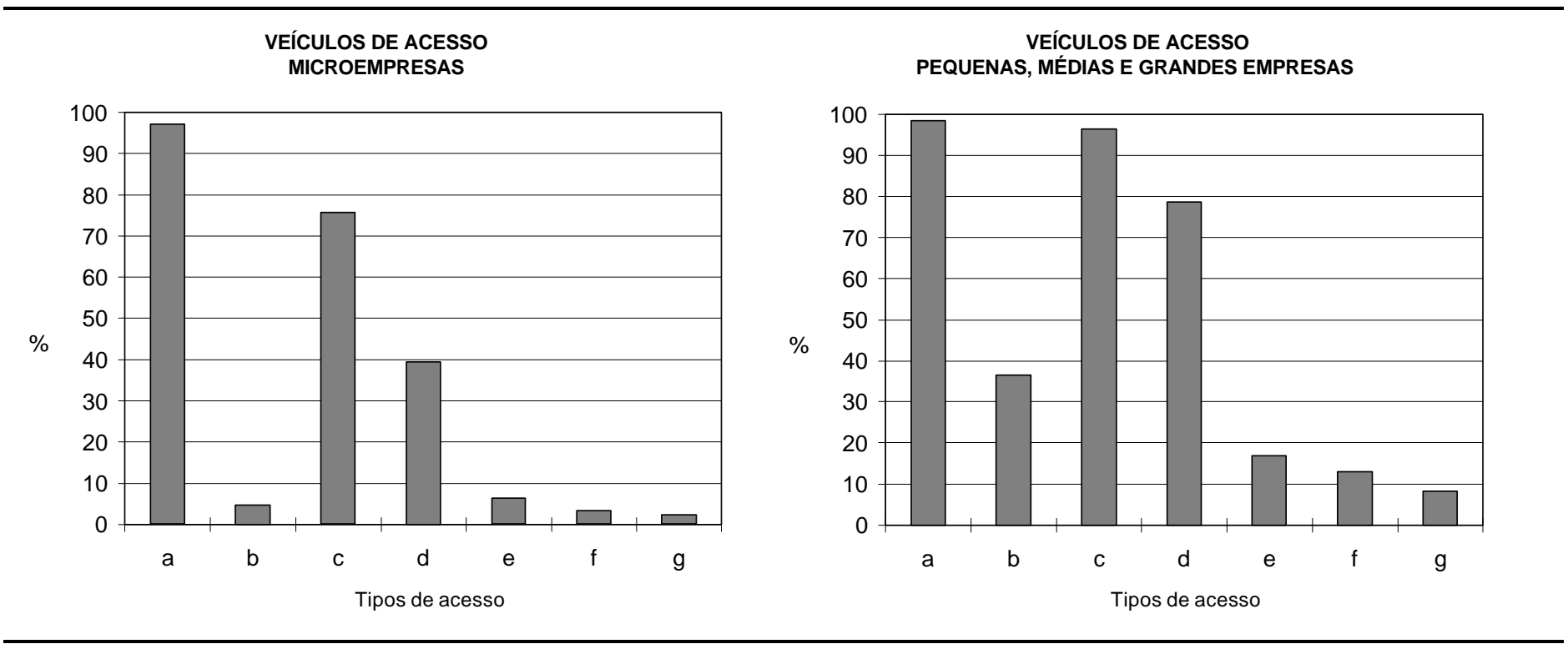

\footnotetext{
${ }^{4}$ Abrindo-se este resultado por porte, verifica-se que os computadores estão presentes em $39,4 \%$ das microempresas, $69,8 \%$ das pequenas, $84,3 \%$ das médias e $91,3 \%$ das grandes.

${ }^{5}$ Os três últimos percentuais foram calculados com base no número de informantes que declararam dispor de computadores, assumindo-se que leitora de CD ROM e redes de comunicação eletrônica nacionais e internacionais, para funcionar, pressupõem a existência destes.
} 


\section{Atividades}

a. Capacitação de $\mathrm{RH}$

b. Adoção de métodos de racionalização da produção

c. Avaliação técnica de fornecedores

d. Avaliação do grau de satisfação dos clientes

e. Atendimentos às exigências dos clientes

f. Monitoramentos do mercado de atuação

No que tange às atividades desenvolvidas pelas empresas para aperfeiçoar seus produtos/serviços, as respostas mais freqüentes estiveram associadas aos clientes, o que pode ser interpretado como fruto da maior concorrência derivada da abertura da economia brasileira, que obriga as empresas a oferecer atenção especial aos consumidores para se manterem no mercado: assim, 69,0\% procuram atender às exigências dos clientes e 59,1\% realizam avaliação do grau de satisfação dos mesmos. Em seguida, surgem capacitação de recursos humanos $(44,1 \%)$, adoção de métodos de racionalização da produção $(41,7 \%)$, avaliação técnica de fornecedores $(36,2 \%)$ e monitoramento do mercado de atuação $(21,2 \%)$. Por outro lado, cerca de $7 \%$ dos informantes não realizam nenhuma atividade visando a melhorar a qualidade dos produtos/serviços.

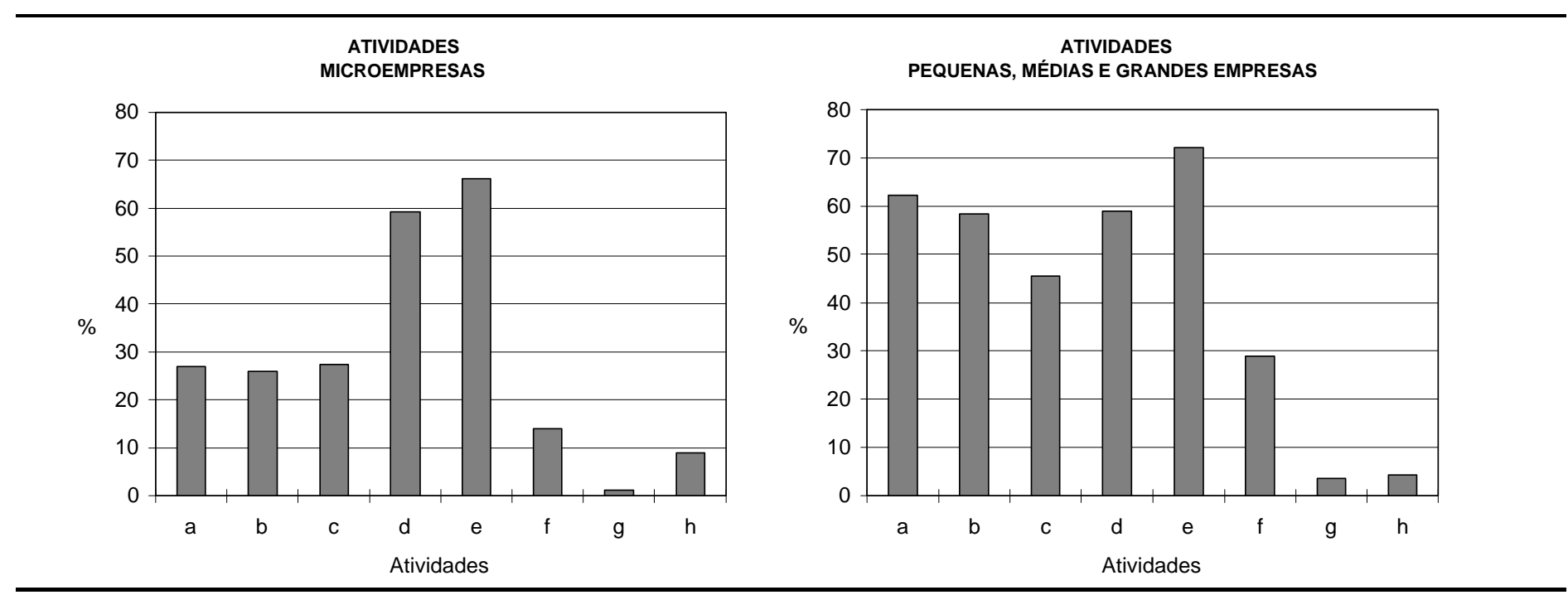

\section{Quais os objetivos das atividades assinaladas no item anterior?}

a. Melhoria de processo/gestão

b. Implantação de programas de qualidade

c. Aplicação da ISO 9000

d. Aplicação da ISO 14000

e. Diversificação de produtos e serviços

f. Manutenção/ampliação da partic.no mercado

g. Outros objetivos

As atividades citadas anteriormente, por sua vez, tiveram, sobretudo, o objetivo de melhorar o processo/gestão ( $59,3 \%$ das respostas) e manter/ampliar a participação no mercado $(54,1 \%)^{6}$. Em seguida, surgem em ordem de importância os objetivos de implantar programas de qualidade (42,4\%) e diversificar os produtos e serviços $(24,4 \%)$. Quanto às Normas ISO, poucas são as empresas industriais envolvidas em programas para certificação: 17,2\% na aplicação da ISO 9000 e 2,9\% na aplicação da ISO $14000^{7}$.

\footnotetext{
${ }^{6}$ Chama a atenção o fato de $54,1 \%$ de as empresas industriais terem como objetivo a manutenção/ampliação da participação no mercado, enquanto apenas $21,2 \%$ delas realizam o monitoramento do mercado de atuação. Em princípio, isto pareceria contraditório, a não ser por duas explicações hipotéticas: o conceito de monitoramento não foi compreendido pelo informante, o que tenderia a subestimar a freqüência de respostas, ou a expressiva maioria das empresas não possui estrutura para realizar este tipo de atividade, embora interessadas nela, visto o elevado percentual de resposta para o objetivo citado.

7 Ressalta-se, com relação à certificação ISO, que os valores para o total da indústria mascaram fortemente as respostas, dado que, quando são excluídas as microempresas, os resultados se alteram bastante: para pequenas, médias e grandes empresas industriais, 29,0\% (ISO 9000 ) e 5,0\% (ISO 14000); para as microempresas, 6,1\% (ISO 9000) e 0,9\% (ISO 14000).
} 
Levando-se em conta os diversos setores de atuação das empresas, as informações na área de compras que melhor auxiliariam no alcance de maior competitividade seriam, fundamentalmente, informações sobre fabricantes/fornecedores $(72,7 \%)$, matérias-primas/insumos $(59,4 \%)$ e máquinas e equipamentos (45,4\%). Em menor grau de importância, aparecem materiais alternativos (31,2\%), qualificação/certificação de fornecedores (26,9\%) e normas/regulamentos técnicos/ especificações para enquadramento (21,3\%). A baixa freqüência de respostas nos dois últimos itens poderia ser traduzida, possivelmente, pela pouca familiaridade/pouco conhecimento, por parte da indústria, da importância de se assegurar tanto a qualidade das matérias-primas e insumos adquiridos, quanto dos produtos a serem colocados no mercado, para maior competitividade da empresa.
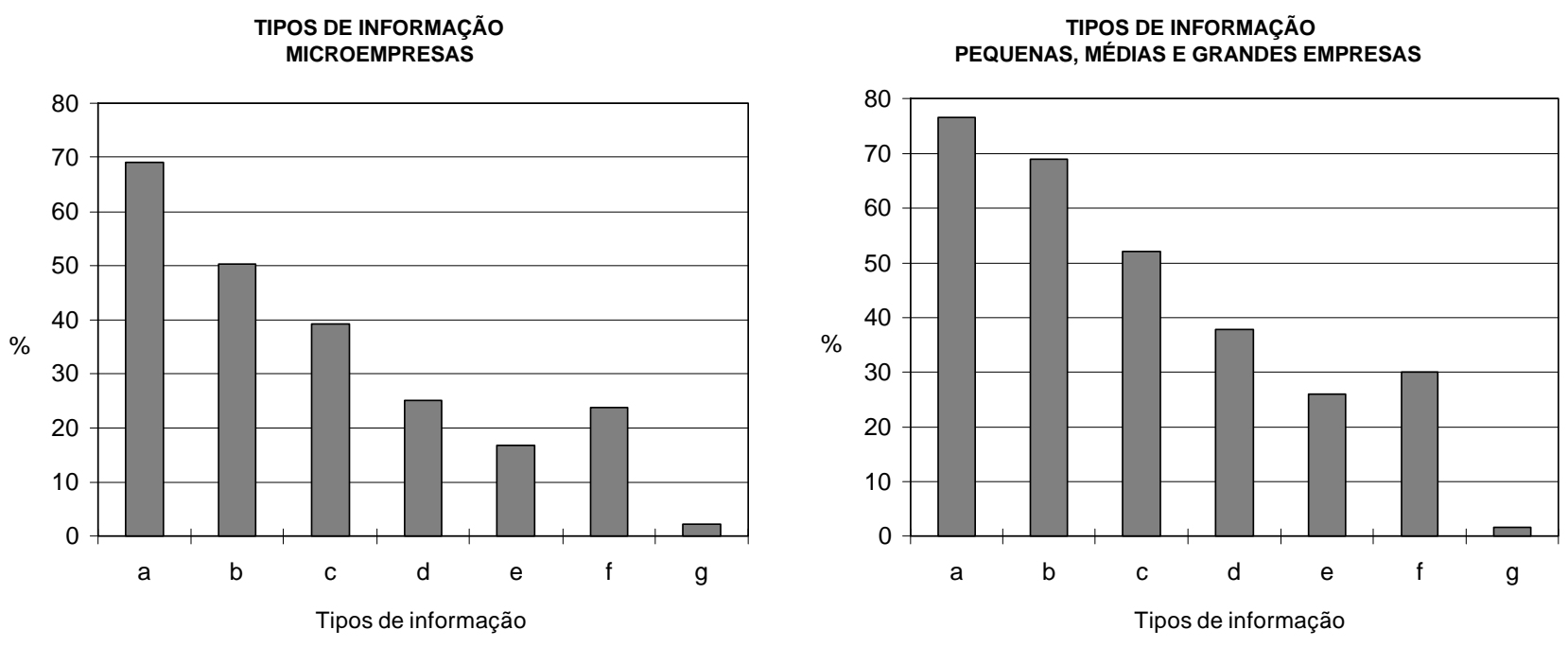

Na área de PRODUÇÃO, quais as informações que melhor auxiliariam sua empresa a alcançar maior competitividade?

Tipos de informação

a. Manutenção de equipamentos

b. Análise e ensaio de materiais

c. Planejamento e controle da produção

d. Tecnol. de processos/produtos/gestão

e. Métodos e técnicas de controle de qualidade

f. Normas, regulamentos técnicos e patentes

g. Tratamento e controle da emissão de poluentes

h. Tratamento e aproveit. de resíduos industriais

. Segurança industrial

$\mathrm{Na}$ área de produção, as três principais informações solicitadas pelas empresas foram planejamento e controle da produção, com $55,1 \%$ das respostas, manutenção de equipamentos, com $53,8 \%$ e métodos e técnicas de controle de qualidade, com $48,0 \%$. Em contrapartida, as informações de menor interesse estiveram associadas a tratamento e controle da emissão de poluentes $(13,1 \%)$ e normas, regulamentos técnicos e patentes $(14,7 \%)$, denotando, mais uma vez, o desconhecimento/pouca familiaridade destes instrumentos como importantes fatores de competitividade para a indústria brasileira no mercado internacional. 
TIPOS DE INFORMAÇÃO

MICROEMPRESAS

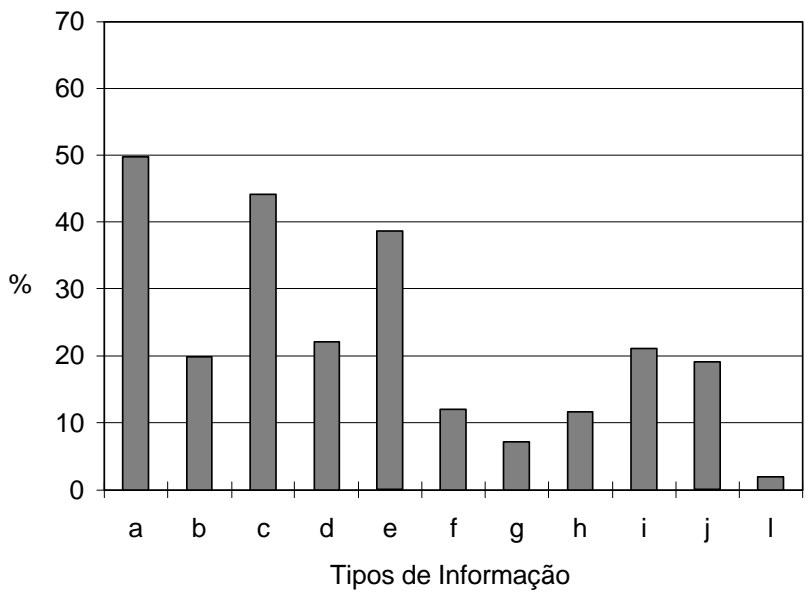

TIPOS DE INFORMAÇÃO

PEQUENAS, MÉDIAS E GRANDES EMPRESAS

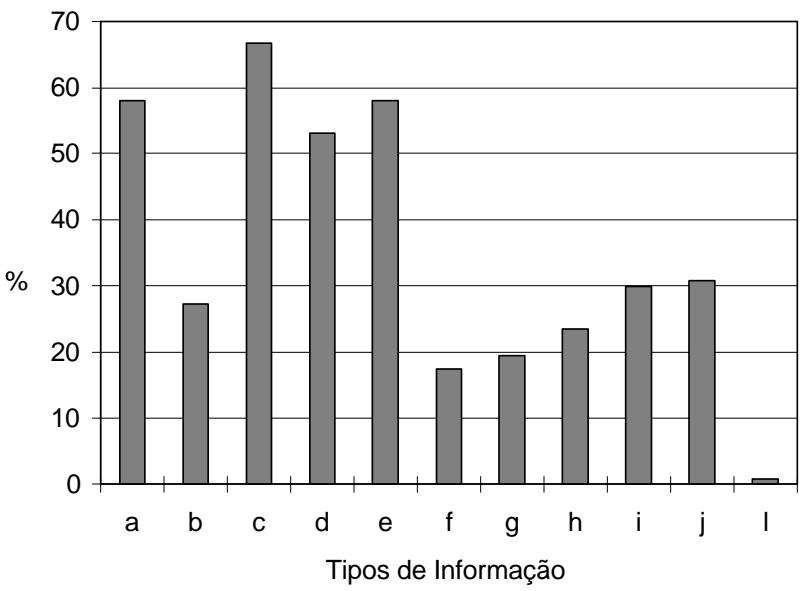

$\mathrm{Na}$ área de VENDAS, quais as informações que melhor auxiliariam sua empresa a alcançar maior competitividade?

a. Mercado nacional

b. Mercado internacional

c. Promoção/divulgação (marketing)

d. Canais de distribuição

e. Políticas de compras do governo

f. Licitações

g. Outras

Com relação à área de vendas, a maior necessidade das empresas industriais reside em informações sobre o mercado nacional (cerca de $79,0 \%$ das respostas) ${ }^{8}$, o que traduz que o mercado interno é significativamente o principal canal de escoamento da produção. Com mais baixos índices de resposta, por sua vez, aparecem políticas de compras do governo, com $11,7 \%$ e informações sobre licitações (14,7\% dos informantes).
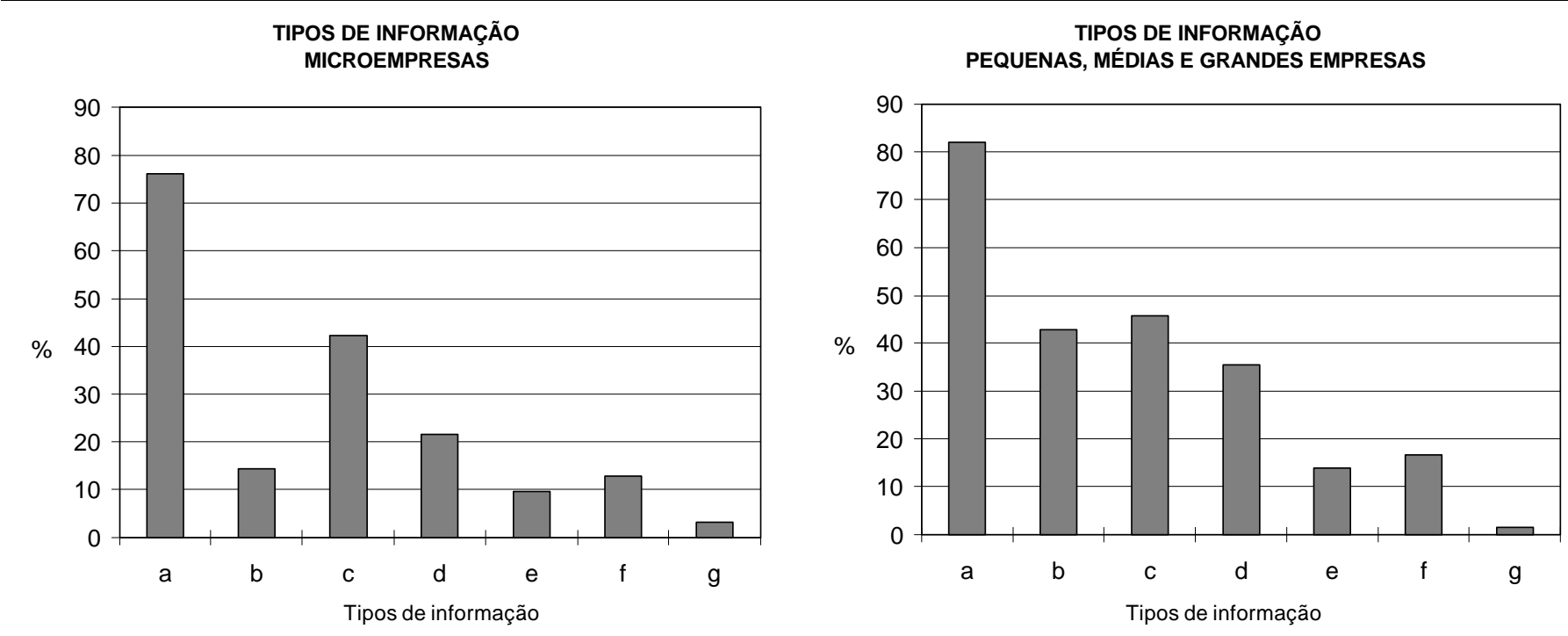

\footnotetext{
${ }^{8}$ Este elevado percentual estaria indicando claramente o desejo de as indústrias obterem informações sobre o principal mercado de atuação (nacional), o que esclareceria o motivo da baixa freqüência de respostas para a atividade de monitoramento do mercado de atuação, conforme nota de rodapé número 4. Para os centros provedores de informação tecnológica, portanto, esta pareceria ser uma área de atuação com grande potencial de exploração, dada a forte demanda do setor industrial.
} 
a. Fontes e formas financiamento

b. Política fiscal/tributária

c. Barreiras não tarifárias

d. Aquisição e transferência de tecnologia

e. Consultores/empresas de consultoria

f. Inter-relacionamento comercial/empresarial

g. Estratégias de atuação de empresas concorrentes

h. Técnicas modernas de gestão

i. Administração de recursos humanos

j. Políticas de preço

I. Marcas

m. Qualidade de vida na empresa/saúde ocupacional

Por fim, na área de gestão, as informações sobre fontes e formas de financiamento continuam sendo a principal necessidade das empresas industriais, conforme revelado por outras pesquisas, com mais da metade das respostas (51,7\%). Em seguida surgem políticas de preços $(45,9 \%$ ) e política fiscal/tributária (inclusive barreiras tarifárias), com $45,1 \%$ dos informantes assinalando este quesito. Embora ainda não significativo, chama a atenção o número de empresas preocupadas em obter informações sobre qualidade de vida na empresa/saúde ocupacional (27,9\%), resultado possivelmente associado aos programas de qualidade em implantação, principalmente nas médias e grandes indústrias.
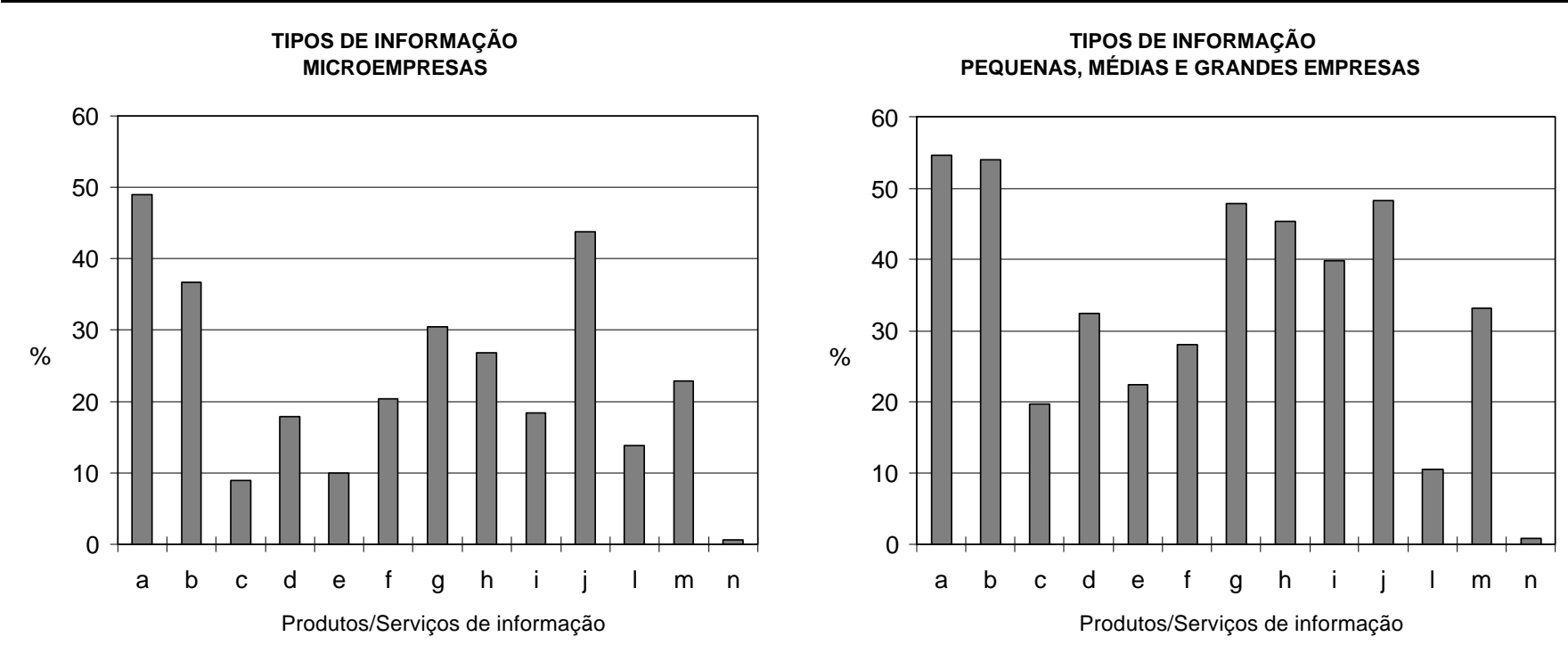

Quais os principais produtos/serviços de informação que melhor atenderiam às necessidades de sua empresa?

Produtos/Serviços de informação

a. Atendimento a consultas técnicas

b. Tradução de documentos técnicos

c. Divulgação de resumos de documentos técnicos

d. Histórico de uma tecnologia (estado-da-arte)

e. Estudos de monitoramento e prospecção tecnológica

f. Realização e divulgação de eventos

g. Divulgação de indicadores da atividade econômica

h. Assistência técnica

i. Extensão tecnológica

j. Oportunidade de negócios/parcerias/joint venture/terceirização 
Como última questão, cujas respostas servem como indicativo direto dos principais produtos/serviços que melhor atenderiam às necessidades das empresas industriais, por parte dos centros provedores de informação tecnológica, tem-se em primeiro lugar a demanda por serviços de informação sobre oportunidades de negócios/parcerias/joint venture/terceirização, com 52,5\% das respostas. Em seguida, os centros deveriam oferecer atendimento de consultas técnicas (pergunta/ resposta) na visão de $45,4 \%$ dos informantes, ficando em terceiro lugar a realização e divulgação de eventos (cursos, seminários, feiras etc.), com $44,5 \%$ das respostas. Os produtos/serviços menos demandados são aqueles associados a tradução de documentos técnicos (12,1\%), levantamento do histórico de uma tecnologia até seu estado atual $(14,2 \%)$ e divulgação de resumos de documentos técnicos $(18,2 \%)$.

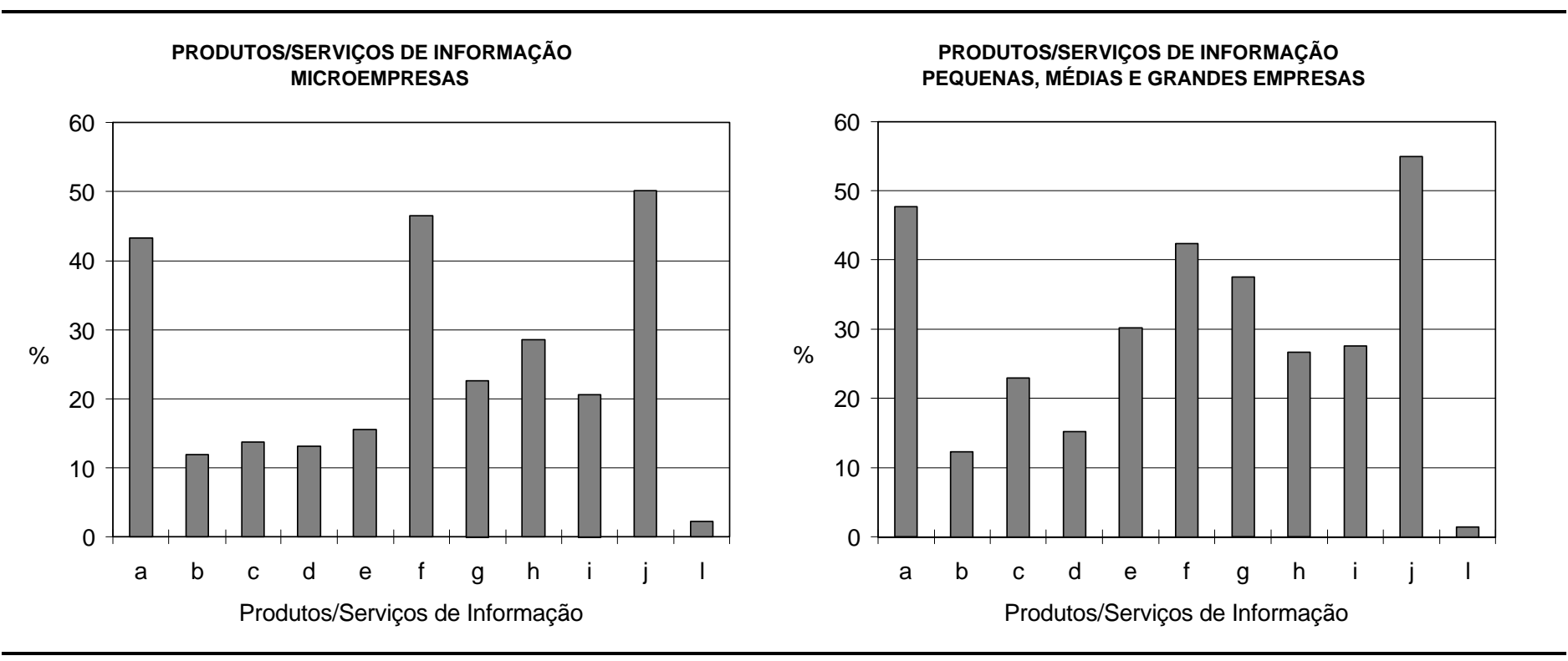

\section{Technological information demand} by the productive sector

\section{Abstract \\ As an iniciative of Technological Information Subcommittee of Brazilian Government in 1996, the survey about the Technological Information Demand by the Productive Sector, by identifying this kind of needs of the industrial setor, looked for providing support data to the technological information centers or institutions for planning and enhancing their activities and services.}

\section{Keywords}

